University of Wollongong

Research Online

Faculty of Informatics - Papers (Archive)

Faculty of Engineering and Information

Sciences

November 2002

\title{
Remote collaborative teaching for computer science
}

\author{
A. Fuller \\ University of Wollongong, annef@uow.edu.au \\ Penelope McFarlane \\ University of Wollongong, penney@uow.edu.au \\ K. Lam \\ INTI College, Sarawak
}

Follow this and additional works at: https://ro.uow.edu.au/infopapers

Part of the Physical Sciences and Mathematics Commons

\section{Recommended Citation}

Fuller, A.; McFarlane, Penelope; and Lam, K.: Remote collaborative teaching for computer science 2002. https://ro.uow.edu.au/infopapers/9

Research Online is the open access institutional repository for the University of Wollongong. For further information contact the UOW Library: research-pubs@uow.edu.au 


\title{
Remote collaborative teaching for computer science
}

\author{
Abstract \\ Like many western universities, the University of Wollongong (Australia) is offering degrees to an \\ increasing number of offshore students. Their usual offshore teaching model involves intensive delivery \\ of course material. Disadvantages of this model include the apparent secondary nature of the offshore \\ academic's role and its unsuitability for technical subjects. In this paper, the authors discuss experiments \\ using Internet technologies to overcome those disadvantages.

\section{Keywords} \\ computer aided instruction, computer science education, distance learning, teaching, remote \\ collaborative teaching \\ Disciplines \\ Physical Sciences and Mathematics

\section{Publication Details} \\ This article was originally published as: Fuller, A, McFarlane, P \& Lam, K, Remote collaborative teaching \\ for computer science, 32nd Annual ASEE/IEEE Frontiers in Education Conference (FIE 2002), November \\ 2002, 1, T1E-1. Copyright IEEE 2002.
}


Session T1E

\title{
REMOTE COLLABORATIVE TEACHING FOR COMPUTER SCIENCE
}

\author{
Anne Fuller, Penney McFarlane ${ }^{1}$ and Kimberly Lam ${ }^{2}$
}

\begin{abstract}
Like many western universities, the University of Wollongong is offering degrees to an increasing number of offshore students. Our usual offshore teaching model involves intensive delivery of course material. Disadvantages of this model include the apparent secondary nature of the offshore academic's role and its unsuitability for technical subjects. In this paper we discuss experiments using internet technologies to overcome those disadvantages.
\end{abstract}

Index Terms - internet technologies in CS education, team teaching, remote collaborative teaching

\section{INTRODUCTION}

As a result of the explosion in Asian demand for western degrees, many Australian universities are now offering degrees via partnerships with colleges in the region. The details of how degree requirements are satisfied vary considerably, however many such arrangements involve off shore students studying at least part of the Australian degree program as external students.

The common teaching model for subjects the University of Wollongong teaches offshore involve an intensive 1 week delivery of course material, with local staff managing the remainder of the session. A disadvantage of this approach is that during the coordinator's visit, the role of local staff appears decidedly secondary in nature, yet they will be the students' primary source of information for the remainder of the semester. Despite regular updates from local staff, it is difficult for the coordinator to remain in tune with student progress, due to their remoteness and lack of contact with the students themselves.

This is of particular concern with the more technical subjects such as those typically offered in a Computer Science (CS) degree. The successful teaching of many CS subjects requires a constant balancing act between coverage of course content and tailoring of the presentation and support materials to meet student needs for each offering. The remainder of this paper reports outcomes from a trial using NetMeeting and WebCT to support remote collaborative team teaching of offshore CS subjects.

\section{THE EXPERIMENT}

This trial involved the teaching of a final year subject in the Bachelor of Computer Science offered by the University of Wollongong (UOW), through INTI College, Sarawak.
WebCT is the class management package supported by UOW. Its facilities for shared designer access were ideal, allowing both the INTI and UOW academic to manage various parts of the course. All course content, assessment and monitoring of student participation involved both academics. The local academic provided training in the use of WebCT, discussion boards, introduced case studies to be discussed and provided onsite support. In addition, he/she presented lecture material in offline lectures.

Students posted questions and discussed issues raised by both academics using the WebCT forums Both academics monitored the discussions to determine where the students were having difficulty, and thus tailored supporting lecture content. To help encourage student participation, individual frequency and relevance of interaction formed part of the subject's assessment.

PowerPoint presentations prepared at UOW were emailed to INTI and loaded onto the PC in their lecture theatre. The UOW lecturer presented the lecture remotely, using NetMeeting, requesting slide changes when required. This was preferred to sharing the PowerPoint presentation as it allowed graphics to be included. Previous attempts at sharing PowerPoint slides resulted in unacceptable transmission delays. These "lectorials" included further elucidation of material delivered in the intensive mode together with feedback on participation posted in the discussion forums.

NetMeeting was also used for synchronous discussions with the UOW lecturer during scheduled laboratory sessions.

\section{RESULTS}

The advantages of this approach include the INTI academic's increased influence in the management of the subject and the continued involvement of the UOW academic throughout the semester, not just during the intensive delivery period. This enabled the coordinator to know when or how to adjust parts of the course in response to student needs.

\section{CONCLUSION}

WebCT and NetMeeting can be successfully combined to continuous support for subjects delivered offshore. This nature facilitates successful remote delivery of more technical subjects.

\footnotetext{
'University of Wollongong, \{annef, penney\} @uow.edu.au

${ }^{2}$ Inti College, Sarawak, kimberly@intisar.edu.my

0-7803-7444-4/02/\$17.00 (C) 2002 IEEE
} 
Session T1E

\title{
POSSIBILITIES FOR COLLABORATIVE LEARNING IN DISTANCE LEARNING - AN EMPIRICAL APPROACH
}

\author{
Ildiko Balazs ${ }^{I}$
}

\begin{abstract}
Students, who participate in distance learning, often experience isolation during their studies. They are only in contact with their tutors, but do not know their peers at all. This happens although learners need feedback not only from instructor, but also from each other in order to create long lasting knowledge. The social capabilities needed to efficiently work in a team or the skills to give supportive feedback and to provide useful arguments can not be learnt in isolation. Internet is able to connect students, who otherwise are not able to meet, which makes it possible to interlock the learning experiences of individuals. Even though Internet exists for a relative long time, the majority of web-based learning contents still support individual learning and do not emphasize the possibilities of a collaborative distance learning. A mean to use these possibilities is to integrate virtual collaborative learning assignments in the curriculum of students participating in distance educational programs.
\end{abstract}

Index Terms - learning, community, text-based communication, time management, virtual collaborative learning

\section{VIRTUAL SEMINAR AT THE DRESDEN UNIVERSITY OF TECHNOLOGY}

In the winter semester of 2001/2002 a virtual seminar was integrated in the curriculum of students at the Dresden University of Technology in Germany and at the University of Szczecin in Poland, complementing face-to-face lectures held at both universities by Prof. Dr. Eric Schoop. In this seminar five German (participation was optional) and eight Polish (participation was obligatory) students worked together in order to solve problems. Participants worked in different groups, ranging from small groups of 2 persons to the entire seminar group. Some groups were rather homogenous, other were rather heterogeneous. Goal was to find the most effective group type for reaching full participation and effective work. Parallel to the virtual seminar a face-to-face version of the seminar was also carried out in Dresden.

This virtual seminar was the first one of a range of virtual seminars within the research and development project IMPULS $^{\mathrm{EC}}$ (Interdisciplinary Multimedia Program for University Education and Self-Organized Learning: Electronic Commerce), supported by the German Federal Ministry of Education and Research. The virtual seminar was carefully prepared with the primary goal of analyzing the possibilities of virtual collaborative learning in multinational learning groups. The results of this research will help to find ways to use the Internet to limit isolation of students in distance education.

\section{PROBLEMS RELATED TO DisTANCE LEARNING}

Distance Learning occurs, when teacher and learner are separated at least at the majority of each instructional process [16]. Before Internet got popular, this form of learning meant simply the sending of printed material to learners. Students then learned on their own, without knowing their peers. Participants so stayed isolated and had to deal with the material without social contact sought by all human beings.

Even now, when Internet became part of the everyday life in many European societies - with 23.51 percent of the population in Western Europe using Internet [4]- distance learning remained a lonely process. Except from a couple of experimental tries, organizations and faculty dealing with distance education, keep on sending reading material and assignments to their students without giving them a chance to build social relationships. Internet changed only the way material is delivered to the students, but often did not reduce isolation. Although modern learning management systems offer integrated communication tools, such as chat or conferencing systems, little has been done to motivate students to use these systems.

In a discussion board, introduced to undergraduate students in the winter semester of 2001/2002 in order to answer their questions related to a lecture, for example, only 7.7 percent ( 41 students) of those participating in the course used this possibility. Only eight of these 41 students (1.5 percent of all students) were active members and produced together with the instructor 67.26 percent of all posts, which could be seen as an average rate of participation in a virtual community [8]. This shows, that without any additional motivation, only a small portion of the students actually use communication tools. Taking the 1.5 percent mentioned above, in a group of 100 students only about two students would be active. It is questionable, however, whether two students are enough to keep a community alive.

The lack of social contact causes a number of serious problems relating to the capabilities of students to create a long lasting and sound knowledge base and skills to work in teams. These problems are not limited to distance education, but can also be noticed in traditional face-to-face higher 'Dresden University of Technology, Department of Business Management \& Economics, Chair of Information Management (Prof. Dr. Eric Schoop), 01062
Dresden, Germany balazs@wiim.wiwi.tu-dresden.de

0-7803-7444-4/02/\$17.00 $\odot 2002$ IEEE

November 6-9, 2002, Boston, MA

$32^{\text {nd }}$ ASEE/IEEE Frontiers in Education Conference

T1E-2 
education. In the German educational system, students mostly participate in lectures in large groups of up to 8001000 students. Undergraduate students often do not participate in seminar groups at all, and even when seminars exists, the number of participants can reach 100 students, meeting often only once every two weeks. These leads to an individualist learning style, where students do not know each other and do not seek contact to and feedback from peers. The lack of discussions in the face-to-face environment effects also the use of community tools in a virtual environment. Students, who are not used to discussions, will also not seek it online.

There are three major problems caused by isolation. The biggest problem is, that students who are not forced to deal actively with the material do not even know what they do not know [11]. When students realize what they do not know, they still do not know what to do about it. Last, when knowledge exists, students often do not use this knowledge. Let's take a look at these problems more closely:

- When students are not provided the possibility to share their newly gained knowledge during a seminar, they will be only confronted with the level of this knowledge - or lack of knowledge - when it is time to take an exam. This leads to the problem, that students do not realize on time what they actually do not know about the subject [11]. Reading material in distance education is carefully put together, since students have to learn on their own. Students read or work with this material but they do not deal with it actively, think about it or look for additional information. This way they can not relize the great variety of ways to reach goals or create new knowledge. In the virtual seminar mentioned at the beginning, students were asked to describe what they think they do know about the subject of the lecture [1]. The overall opinion was, that they know too little, although later questions regarding this subject were answered without any former preparations. The "virtual" students did not know less, then the face-toface students, they just knew that there is a lot more to know.

- Material in distance education - and in face-to-face courses - is put together carefully. Students only have to read this material and answer questions in a given fashion, but they do not need to look for a solution by themselves. In a situation, where this exact guidance is not given, students can soon feel frustrated. In the virtual seminar this meant that students at the beginning did not know where they should look for additional material needed to reach goals. Instead of actively looking for solutions or asking questions they waited for answers and felt left alone, when these answer were not automatically given by the instructor.

- Many students can not discuss about the material they are dealing with, although they can answer questions related to it. They simply lack reasoning abilities. Even those students, who have a sound knowledge, often fail to build own opinion or to apply this knowledge in arguments. Similarly, students can not reach back to the their knowledge in order to solve problems, for the connection between problem and theory is missing. Theories remain so theories without relating them to every day life or real problems. Some distance education programs include face-to-face sessions, that can be used for problem solving exercises, but time is too short for an active participation. Problems and materials are significantly simplified in order to fit as much material as possible in the face-to-face session.

Students do not only need abilities to identify and use their knowledge, they also need to be able to share this knowledge. The world is complex, and one person can impossibly know everything needed. Organizations need employees, who are able and willing to share knowledge in order to gain competitive advantages. People must not only be willing to tell what they know, they also have to be willing to look for information provided by others. Additionally, more and more organizations set up interdisciplinary teams to solve different problems. People in such teams need social capabilities in order to work effectively. This means skills, such as readiness for compromises or for accepting different perspectives, just as much as the ability to deal with critique or to give supportive feedback. These abilities are often taken for granted. The virtual seminar, however, showed that students do not have these capabilities. One group had to be spit, because one member (a young German without any experiences in working with a group) could not accept the different opinion of the other members. Instead of looking for a common solution and providing supportive critique, he hurt the other members in a very personal way, which caused the group to work very insufficient.

Distance Learning, even if the possibility of using a virtual learning community is given, often fails to create an environment, in which students can gain such abilities. Faculty often oversees the importance of this, for outcomes related to social capabilities are not considered academic. Such outcomes are for example the increased competence in working with others, an increasing self-assurance or a personal insight [12]. Without a socially welcoming educational environment, the possibility for students to drop out is greater due to lack of social bonds.

\section{LEARNING COMMUNITIES AND COLLABORATIVE LEARNING}

Collaborative learning is not a new issue, although higher education often does not make use of this form of learning. Collaboration needs more time and effort not only from students, but also from instructors, than one-way lecturing, hence it is rather ignored in traditional education at Universities.

Still, students usually look for a community, where they can informally work together to some degree. The degree of

November 6-9, 2002, Boston, MA 
sharing learning between students depends on the society to which the student belongs to. In face-to-face environments, where students know each other personally, informal learning communities often exist without external support. These learning communities can support the development of social capabilities, discussed earlier. It can help students learn to work in collaborative groups instead of learning individually. In the next sections learning communities and collaborative learning will be introduced.

\section{Virtual Learning Community}

A learning community is a group of learners with common interests, goals and purposes. In such communities students share their experiences about their learning situation and help each other to master educational challenge on their own. Learning communities arise automatically everywhere, where people learn together. Although in K-12 education it is a common feature, higher education often isolates students, who then no longer see themselves as part of a community. In distance learning students can not create such a community at all, for they do not see each other in the majority of the time.

With the emergence of Internet, learning communities are no longer limited to a local group of students. With the help of different communication tools, students can create a virtual learning community that can work similar to a traditional face-to-face community. In a virtual environment, however, communication is different than in a usual face-toface situation. In the later simply the fact, that people are in the same room, can lead to a conversation of some kind, since most people are uneasy being in the same room without talking to each other. The surrounding alone can help to find the first topic that can lead to an even deeper conversation. In a virtual environment on the other hand, conversation has to come first in order to create the environment. Online it is easy to stay quite, and just listen to what others say or simply ignore the existence of the community.

For a virtual learning community to emerge and to keep it active, more is needed, then just creating a web site. The anxiety of an unknown environment must be taken by the faculty. Being in a new group or situation - face-to-face or virtual - is often frightening. In a virtual situation it is easier to keep quite and try to escape the new and unfamiliar environment. This can first seem as advantageous, but on the long turn isolation only leads to problems. People, who do not know each other at all, must first learn, that they are not alone. Faculty should help students to look at the virtual learning community as a possibility to learn more and easier, and as an environment to get to know peers and to exchange ideas, tips and thoughts. Without the help of the faculty less then ten percent benefit from the existence of such communities, and a lot more do not even realize the importance of it. When faculty consciously wants to use the advantages of a virtual learning community, such as social bond and the support of social capabilities, student have to be motivated to voluntary participate in the community, just as they would do in a traditional educational situation.

In the virtual seminar students received guidelines for working and for getting a grade. This guideline included the need to write posts at leas twice a week. At the end, after personal interviews, it turned out, that the rule to write posts caused students to feel uneasy. Before this rule got effective, participation was lower, but students enjoyed working together. Afterwards, even the active students reported that they spent a long time thinking about possible posts, and wrote only because they had to, instead of writing because they wanted to share their thoughts.

Learning communities should be learner-managed and open-ended to give students the responsibility for reaching their goals [5]. This way, students do not wait for instructions, but rather look for ways together with peers, which is an important ability for future life-long learners. Since work in a community should be voluntary, full participation can not be reached. It should also not be aimed, for it can lead to a serious problem of information overload. When full participation is needed, the use of virtual collaborative learning is advisable.

\section{Collaborative Learning}

Johnson \& Johnson defined collaborative learning as the instructional use of small groups so that students work together to maximize their own and each other's learning outcomes [7]. Here we can see the major difference between a virtual learning community and collaborative learning. A community is a relatively large group of learners, where the majority of participants are rather inactive listeners. In a collaborative group of students full participation is aimed. Here students learn in a smaller, more stable and better structured environment, where the social bond between members is stronger then in a community. In a collaborative group leadership is more important, too, for the group has to reach set goals in given and limited time.

In a collaborative situation members of a group strive together for success, that is beneficial to the individual and to the whole group. Every group member is responsible for the success of the whole group. Through collaborative learning students are forced to use the knowledge gained in other situations - for example in lectures - in order to reach mutual goals. Here students must learn to share resources and to explain their knowledge to others. These are important skills for future members of large organizations in the knowledge society of today. Collaboration means, that students do not seek individual success, for this can easily lead to competition between. group members. Competition can make the group turn into a so called pseudo working group, which rather hinders the work of the individuals [7].

Only in a fully collaborative group can the knowledge of one member complete the knowledge of the others leading to a better result, than what the individuals could reach alone. Such a collaborative group emerges, when positive interdependence exists between the members. This

November 6 - 9, 2002, Boston, MA

\section{$3^{\text {nd }}$ ASEE/IEEE Frontiers in Education Conference}


interdependence - for example limited resources, mutual identity, or common rewards - makes it clear, that the members can only reach their goals, when they cooperate. In the process of collaboration the knowledge of the individuals are made public, meaning that this knowledge becomes clear not only to the individual - which is not always the case but also to other members of the group [12]. Being able to identify existing knowledge helps to identify needed knowledge, and helps to find ways to gain the needed knowledge or information. There are also other benefits of collaborative learning:

- Students working in collaborative groups are more engaged with the material, than those just listening to an instructor. This leads to a better mastery and retention of the material discussed.

- Students working together learn to cooperate with others. This means, that they learn to accept different opinions. They also develop reasoning strategies of higher quality, since they are forced to express their opinions and to convince others to reach best possble outcomes.

- Members of a collaborative group can also reach better results, for interaction with others can help to create new ideas and solutions, that alone might have been stayed undiscovered even by the individual himself.

- The social bond of group members responsible for mutual success is also tighter then in a group, where learners work simply individually putting their own small parts together, instead of working together. This social bond drives the group to more success and lessens the possibility for giving up.

\section{Challenges Regarding VIRTUAL COLLABORATIVE LEARNING}

Virtual collaborative learning does not occur automatically by simply putting students in a group. This leads to no success in either a traditional face-to-face situation, nor in a virtual environment. Besides challenges, such as creating positive interdependence, or formulating sufficient assignment that is needed in face-to-face collaborative learning as well, additional challenges are faced, when students are expected to cooperate in virtual environments. Here only the special challenges regarding virtual environment will be considered. Challenges include:

- Text-based communication

- Time management

- Technical problems

- Independent learning and flexibility

\section{Text-based Communication}

Virtual collaborative learning is based on the interaction between group members, based on some kind of text -based communication. This can be either synchronous, with 0-7803-7444-4/02/\$17.00 02002 IEEE members chatting real time, or asynchronous, with members interacting at any time and in any place.

The result of a text-based communication is the lack of meta communication. Meta communication supports the process of information exchange between members of an interaction, with giving additional meaning to what was said. The speaker can so specialize the meaning of his words with the help of mimics, gestures and voice. He can also see on the reaction of the listener, how and whether his words were understood, changing immediately words and gestures in order to limit misunderstanding [15]. The risk of misunderstandings are even higher, when members of the group have different socio-cultural backgrounds. The students of the virtual seminar reported that they misunderstood up to 30 percent of the posts and needed additional clearing posts or e-mails. The inclusion of emoticons and guidelines for participation can help to reduce misunderstandings. By the creation of virtual collaborative learning environment, faculty has to make sure, that students are aware of the new situation. They must feel, that this is a new environment, where old norms and traditions do not function well without the adoption of a new set of rules.

Although students of the virtual seminar were familiar with text-based communication - they all used omail and short messages - they still made a couple of mistakes, that caused the discussion to be less transparent. Some students posted long messages with insufficient title. This lead to frustration due to information overload. Those students, who could not participate every day, soon lost track of the discussion. Long messages made it difficult to reflect to them and so to discuss about the topic. Since title was not chosen with care students often learned about the content of the message in the end interview, although it contained exactly the information they were seeking. Another problem arouse from the international nature of the seminar group. The native speakers did not at the beginning pay attention to use a simple language, which lead to misunderstandings on the non native speaking side.

Text-based communication also has advantages. The interaction focuses on the content of the messages without considering the appearance of the person posting the message. Opinions and thoughts can be transmitted without external influencing factors, such as gender, look or handicap. The inside of the participants will be visible and the outside unimportant [10]. This leads to a greater equality among participants. Time to think about messages in an asynchronous environment also leads to equality, for the more dominant participants can not interfere when quite students express themselves, so every student has equal chances to participate.

Some students of the virtual seminar mentioned the chance to actively participate in the group as the biggest advantage. These students did not speak up in traditional environments for different reasons, such as lack of sufficient language skills, some sort of speech defect or simply feeling uncomfortable speaking up in a large group.

November 6 - 9, 2002, Boston, MA 


\section{Session T1E}

\section{Time Management}

Time is an important issue in virtual collaborative learning, especially, when asynchronous communication tools are used. Time issues can be grouped in two categories: time needed to solve a problem, and the continuous nature of working in a virtual environment.

Text-based asynchronous communication needs a lot more time, than communication in a face-to-face situation. Reading and writing alone needs more time, then speaking and listening. Considering, that the group members do not participate at the same time, it becomes clear, that solving a problem in a virtual environment takes more time, then solving the same problem face-to-face. Assignments have to be adjusted to this situation. More time has also advantages. Students in an asynchronous environment have more time to think about their posts. Instead of answering a question rapidly, they can think about their answers or questions. This way students can engage with the material more deeply and can prepare themselves more intense. Time can also be used to look for additional material needed to answer questions or to solve the problem.

Faculty must look at the second time issue even more carefully. In the virtual environment time has a different meaning. There is no set time to work, students can not participate at set times and then turn to other subjects. Work is there all the time. It is not enough to participate once a week for 90 minutes, as in usual face-to-face situations. Students have to check the discussion board more often to be able to keep up. Learners need more self-control in working in a virtual environment. The continuous nature of virtual collaborative learning means that work becomes part of the students every day life. They can write posts at any time and there may be something new at any minute of the day. All students of the virtual seminar reported, that they had the feeling of continuously dealing with the seminar. While reading an article they thought about, how this could relate to their online work, at other classes they thought about how they could use the new information to solve the problem presented to them in the virtual seminar. This might sound well, but it can easily lead to frustration by students.

Faculty must provide proper guidance to help students manage time in order to work efficiently without getting lost in the work. Students might need to be guided back to the problem, when wondering off or getting too decply involved with part of the material. Faculty must also support students, when time-based problems are discovered, in order to cut back developing frustration.

\section{Technical Problems}

Virtual collaborative learning can not take place without technical support. Participants will only meet each other with the help of some kind of communication tools. Many virtual educational programs face serious technical problems. Students then deal more with technical difficulties then with the work itself [20]. This leads to drop-outs and to less activity, which then leads to information overload by those, not able to participate as often as others.

In the virtual seminar the technical possibilities of the students lay at about 60 percent -100 percent meaning technical possibilities, that do not hinder the work at all with a standard deviation of 20 percent. Some students possessed proper Internet access and a fast computer, but some did not even have a computer at home and had to use the computer pool of the university. The various technical possibilities of the students limited work, for those being able to $\log$ in at any time often had to wait long, to receive answers from those having major technical problems. On the other side some students kept on writing frustrated e-mails complaining about the discussion going on at a speed, that they could not follow due to not being able to log in often enough.

Before launching a virtual collaborative program, facuity must consider, that Internet access is not yet common. In the USA Internet access reaches more then 50 percent, in West Europe only about 23 percent of the population can reach Internet, in Eastern Europe this is even less common, with only about 5 percent. The communication tool used and the content provided should be adjusted to the possibilities of the target group. Where Internet access is expensive, faculty should consider to use a tool, that enables off-line work, and that does not need long loading time. Decision should not be technical-based, but learner based.

\section{Independent Learning and Flexibility}

Working in a virtual environment needs more motivation and self-control then participating in a face-to-face group. Students have to manage their time and look for additional resources on their own, without receiving additional instructions from the tutor. This is one of the reasons, why older and more self-conscious students can benefit more from a virtual learning environment, than others [17]. In the virtual seminar students with less experiences - younger students who participated only in lectures before the virtual seminar - often felt themselves left alone, when assignment was not accompanied with exact instructions. One student worked only with the material handed out and did not look for additional resources at all, even when he felt that information provided was not enough to solve a problem. This student soon gave up the active work and did not enjoy the work any longer.

Virtual work on the other side provides more flexibility for those ready to work without much structure provided by faculty. Students reported that they enjoyed working at any time of the day, so they could deal with the seminar when they were really ready for working, and not when class was set by faculty. Another advantage regarding flexibility reported by the students was, that students themselves could set the pace of learning and the amount of information used to understand the material. 


\section{Session T1E}

\section{CONCLUSION}

This first project showed only the areas of interest, that should be researched more closely in order to find effective ways to include virtual collaborative learning to reduce isolation in distance learning. Students of the frst virtual seminar showed that it is important to keep on looking for ways to integrate such assignments. The Polish students, who otherwise would not have had any chance to deal with the material between the three 2-day lecturing blocks, reported that despite of major technical difficulties they enjoyed working in the seminar, because this way they could engage with the material, could ask questions and could receive help from German students. German students also spoke positively about the project, despite of all the difficulties they had to face, because of the nature of the project.

The enthusiasm of the students shows, that it is important to look at the difficulties again, and to try out different methods to limit them. For this reason, the next project is being developed now using the results of the evaluation of the first project. This second project will take place in the summer semester of 2002, changes include:

- a more focused development of the assignments in order to better fit the characteristics of a virtual environment,

- a higher concentration on group dynamics in order to support the development of fully collaborative groups,

- and a more focused guidance from the background, giving feedback only when needed, and letting students work on their own.

\section{ACKNOWLEDGMENT}

I would like to thank Prof. Dr. Eric Schoop, head of the Chair of Information Management at Dresden University of Technology, Department of Business Management \& Economics for his kindly support during this research.

\section{REFERENCES}

[1] Balazs, I. \& Schoop, E. "Arguments for Building Learning Communities in Higher Education - First Results of an Empirical Research " in World Congress: Networked Learning in a Global Environment, Challenges and Solutions for Virtual Education, Proceedings-CD, ICSC-NAISO Academic Press, Canada, The Netherlands, 2002

[2] Bernal, V. "Building Online Communities: Turning Assumptions into Success",

http://www.benton.org/Practice/Community/assumptions.html last access: 01/2002

[3] Bonk, C, "A Ten Level Web Integration Continuum for Higher Education: New Resources, Partners, Courses, and Markets", http://php.indiana.edu/ cjbonk/paper/edmdia99.html, last access: $12 / 2001$

[4] CIA, "World Factbook 2001", http://www.cia.gov/cia/publications/factbook/, last access: 02/2002
[5] Coomey, M, \& Stephenson, J. "Online Learning: it is all about dialogue, involvement, support and control - according to the research ", in Stephenson (ed..): Teaching \& Learning Online: Pedagogies for New Technologies, Kogan Page, London, 2001, pp. 37-53.

[6] Hall, E.T. "Beyond Culture", Anchor Books, New York, 1989

[7] Johnson, D. W. \& Johnson, Roger T., "Learning Together and Learning Alone: Cooperative, Competitive, and Individualistic Learning", Allyn and Bacon, Boston, 1999

[8] Kim, A. J., " Community Building on the Web: Secret Strategies for Successful Online Communities", Peachpit Press, Berkeley, 2000

[9] Kimball, L. "Managing Distance Learning - New Challenges for Faculty ", http://www.co-i-l.com/cail/knowledgegarden/rc/index.shtml, last access: 12/2001

[10] King, S.A. "The Psychology of Cyberspace ", http://webpages.charter.net/stormking/cyberpsy.html, last access: $01 / 2002$

[11] Koschmann, T, Kelson, A. C, Feltovich, P-J, Barrows, H.S. "Computer-Supported Problem-Based Learning: A Principled Approach to the Use of Computers in Collaborative Learning" in Koschmann, T. (ed): CSCL: Theory and Practics of an Emerging Paradigm, Lawrence Erlbaum Associates, New Jersey, 1996

[12] McConnell, D. "Implementing Computer Supported Cooperative Learning", Kogan Page, London, 2000

[13] McMahon, M, "Social Constructivism and the World Wide Web -a Paradigm for Learning", http:/www.curtin.edu.au/conference/ascilite97/papers/Mcmahon/Mc mahon.html, last access: 12/2001

[14] Oliver, R., " Exploring the development of critical thinking skills through a Web-supported problem-based learning environment" in Stephenson, J. (ed.): Teaching \& Learning Online: Pedagogies for New Technologies, Kogan Page, London, 2001, pp. 98-111.

[15] Pálffy, K. "Bevezetés a pszichológiába ", Nemzeti Tankönyvkiadó, Budapest, 1989

[16] Palloff, R. M. \& Pratt, K. "Building Learning Communities in Cyberspace: Effective Strategies for the Online Classroom", JosseyBass, San Francisco, 1999

[17] Palloff, R. M. \& Pratt, K. "Lessons from the Cyberspace Classroom: The Realities of Online Teaching", Jossey-Bass, San Francisco, 2001

[18] Salmon, G. "E-Moderating: The Key to Teaching and Learning Online", Kogan Page, London, 2001

[19] Schlais, D. \& Davis, R. "Distance Learning through educational networks: the global view experience" in Stephenson, J. (ed.): Teaching \& Learning Online: Pedagogies for New Technologies, Kogan Page, London, 2001, pp. 112-126

[20] Schulmeister, R. "Virtuelle Universität - Virtuelles Lernen", Oldenbourg Verlag, München, 2001

[21] Schwabe, G., \& Valerius, M. "Kollaboratives Lemen mit neuen Medien", in WISU 10/01, 2001, pp. 1360-1368

[22] Stegbauer, C. "Grenzen virtueller Gemeinschaften: Strukturen internetbasierter Kommunikationsforen", Westdeutscher Verlag, Wiesbaden, 2001

[23] Stephenson, J. "Learner-managed learning - an emenging pedagogy for learning online" in Stephenson, J. (ed.): Teaching \& Leaming Online: Pedagogies for New Technologies, Kogan Page, London, 2001, pp. 219.224 